\title{
Digital Impressions - A Review of Latest Technology in Dentistry
}

\author{
Ina Bhupesh Patel ${ }^{1}$, Bhupesh B Patel ${ }^{2}$, Ruchir Patel ${ }^{3}$
}

\section{Quick Response Code}

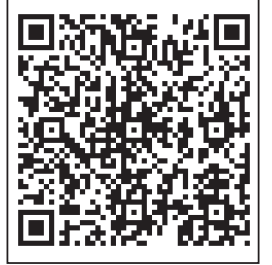

doi: $10.5866 / 2015.7 .10142$

${ }^{1}$ Professor and Head of the Department

Department of Prosthodontics,

AMCMET Dental College, India

2Professor, Department of Oral Pathology,

Dharamsinh Desai University,

Nadiad, Gujarat, India

${ }^{3}$ Private practice at Ahmedabad

Gujarat, India

\section{Article Info:}

Received: April 8, 2015

Review Completed: May 10, 2015

Accepted: J une 11, 2015

Available Online: April, 2015 (www.nacd.in)

(c) NAD, 2015 - All rights reserved

\section{Email for correspondence:}

rucheer.5690@gmail.com

\begin{abstract}
:
Tolearn about current technol ogy trends in the field of dentistry. Tolearn about the use of digital impression machines for taking impressions. To learn about process of taking the impressions. To learn about the shortcomings of digital impressions.
\end{abstract}

DATA: In the article we will know more about digital impressions by learning in detail about the three different scanner systems in use and also comparing them. We will also learn about cons of digital impressions. Also information about the whole process of taking digital impressions is provided in the article.

SOURCES: References from various articles have been taken in the article. All of the sources have been stated under references at theend. Wikipedia and Googl e have al so been used extensively for various references.

STUDY SELECTION: The main purpose of this article is to know more about the latest technology in dentistry. I mpression taking has been an integral part of dentistry. With the introduction of digital impression the whole process of taking traditional impressions which involved a lot of complex steps like tray selection, material mixing, loading, tray placement and removal has been removed and the process of taking digital impressions is lot easier and faster. So to know more about the digital impression this study is selected.

CONCLUSION: Dentistry is expanding every day, the field of impressions has been quickly growing with the help of advancement in technology and introduction of digital impression scanner systems.

Key words: Digital Impressions; Technology; Scanner; Systems; CAD-CAM; Technician; Machines

\section{INTRODUCTION}

Dentistry is truly a great profession for those of us who love gadgets, technological advances and dreaming of the possibilities of future devel opments. with the use of technology in dentistry, things have become a lot easier to do, and with the introduction of digital impressions the process of taking impressions have become much easier to do as this 
involves much simpler steps. Digital impressions are a virtual replica of traditional impressions with impression quality far superior then even the best of traditional impressions. Digital impression systems, such as the Lava Chairside Oral Scanner by $3 \mathrm{M}$, the CEREC AC by Sirona, and the Cadent iTero system are used to take a digital "impression" of the teeth, rather than use the traditional gooey impression material that is necessary to obtain the final impression for a crown, bridge, or veneer. ${ }^{1}$ By moving from a traditional impression technique to technology that incorporates high speed image processing algorithms and real time modelling, the software creates images that can be saved to a computer and can be directly sent to a laboratory having CAD-CAM Machinery for making the crown or bridge. In office milling machines are also available to design and fabricate the crown while patient waits. The present review discusses the same.

\section{DIGITAL IMPRESSION MACHINES}

There are 8 systems available from 6 different companies, out of which currently 3 main systems are in use for digital impression making, such as the Lava ChairsideOral Scanner by 3M, the CEREC AC by Sirona, and the cadent iTero system.

\section{LAVA CHAIRSIDE ORAL SCANNER BY 3M}

The Lava C.O.S. scanner contains 192 LEDs and 22 lens systems with a pulsating blue light and uses continuous video to capture the data that appears on the computer touch screen during scanning. Almost 2,400 data sets are captured per arch. After scanning the image can be rotated and magnified and also be converted from 3D image to $2 \mathrm{D}$ image. The opposing arch is scanned and then occlusal image is taken by closing the patient's mouth in occlusion. This system requires light powder coating of the tooth prior to scanning (Figure 1). ${ }^{2-4}$

\section{CEREC AC BY SIRONA SYSTEMS.}

This Scanner operates using visible blue light emanating from light emitting diodes (LEDS) with shorter wavelengths of light than previous CEREC models, increasing the accuracy of the scan. The ability to take images is more quick than previous models due to continuous capturing of a series of images by the scanner once in position. The occlusal scanning is done in the same way, but in this system digital on screen articulating paper shows where there are contacts (see image below) and images of interdigitation can be seen to see inter-occlusal distance. Cerec Connect is needed in the laboratory to transfer the images. This system also provides a digital version of the proposed restoration prior to fabrication. This system also requires powder coating for proper image reproduction (Figure 2 and 3). ${ }^{2-4}$

\section{CADENT ITERO SYSTEM BY ALIGN TECHNOLOGIES.}

The iTero chairside digital impression scanner utilizes parallel confocal imaging to capture a 3D digital impression of the tooth surface, contours and gingival structure. It captures 100,000 points of laser light and has perfect focus images of more than 300 focal depths. The system captures 3.5 million data points for each arch. This is a newer system then the above two systems and can scan even if the scanner touches the tooth and does not require powder coating. It also gives a series of verbal and visual prompts to guide the clinician in scanning process. The occlusal registration process is same i.e. taking image by closing patient's mouth in centric (Figure 4). ${ }^{2-4}$

Comparison between the 3 scanner systems is given in Table 1.

\section{IMPRESSION TAKING METHOD ${ }^{5,6}$}

The method to take the impression is very easy compared to the traditional impression technique, provided the required steps to take the impression are followed properly. The steps which need to be followed are

1. First, the software of the system should be ready and the handle with camera should be ready to scan.

2. Second, the prepared tooth should be dried and isolated and tissue should be retracted with a gingival cord, retraction is a must for taking digital impressions as scanner might not be able 


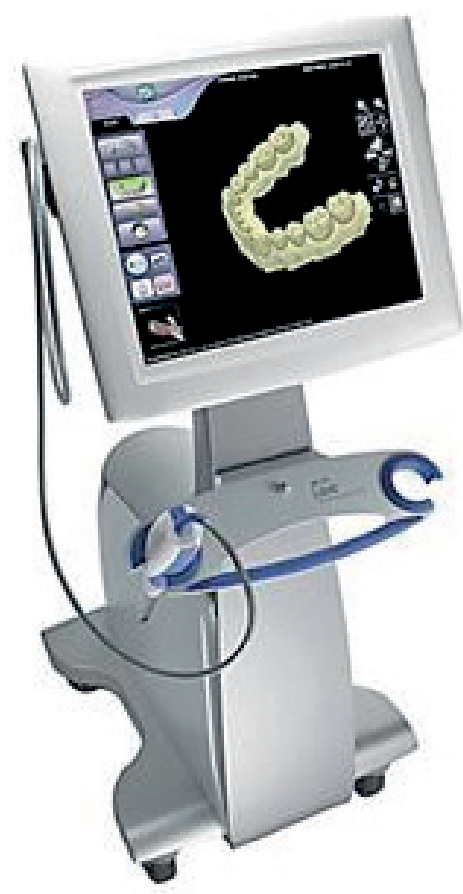

Figure 1: 3M lava's chairside scanner with computer and handheld software.

Courtesy: www.wikipedia.com and image search. ${ }^{9}$

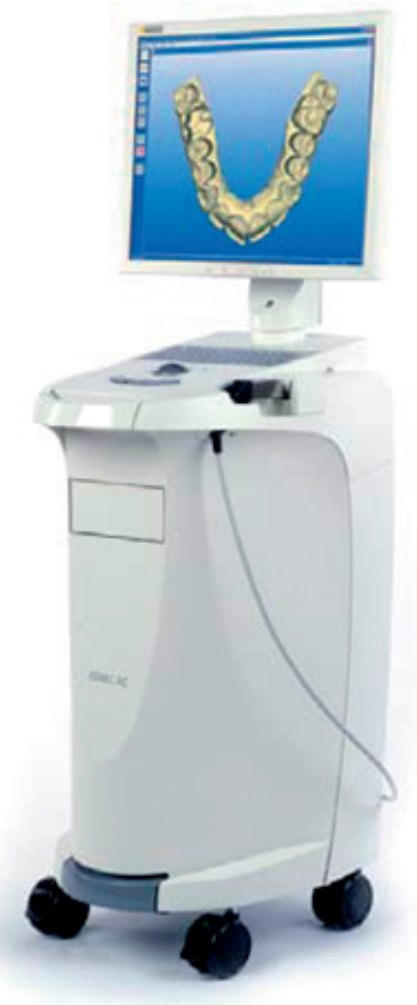

Figure 2: Cerac AC system by Sirona. Courtesy: www. wikipedia.com and image search. ${ }^{9}$

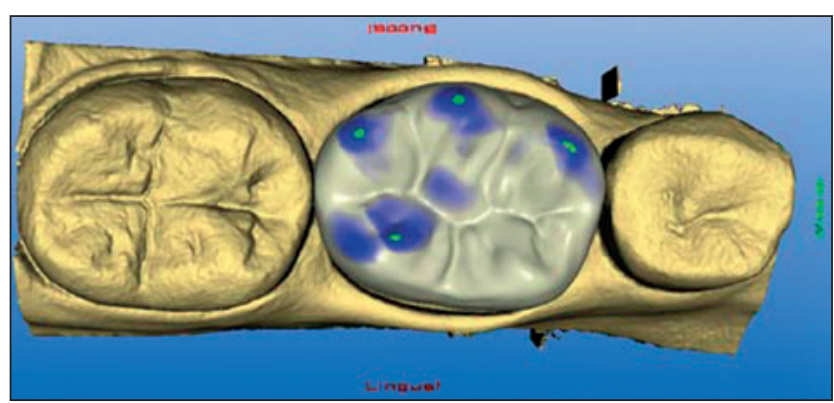

Figure 3: On screen articulating paper marks. Courtesy: www.wikipedia.com and image search. ${ }^{9}$

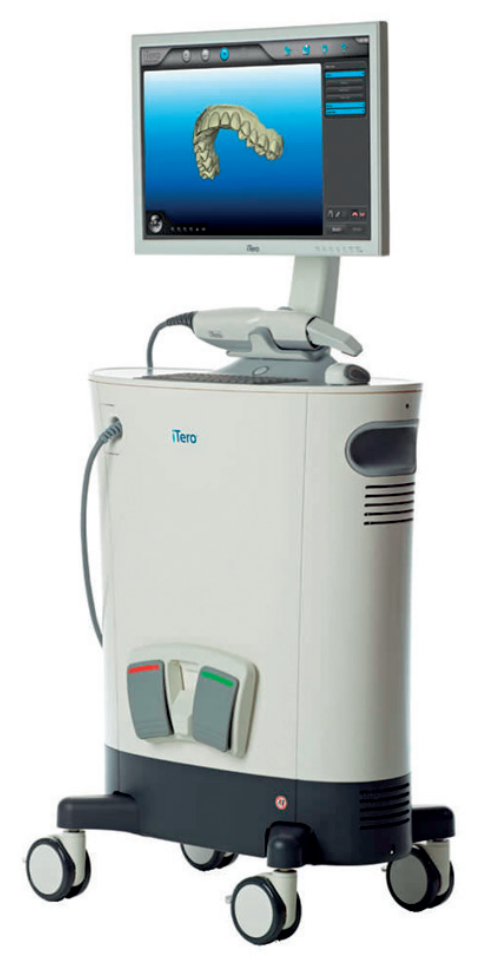

Figure 4: Cadent iTero system. Courtesy: www.wikipedia.com and image search. ${ }^{9}$

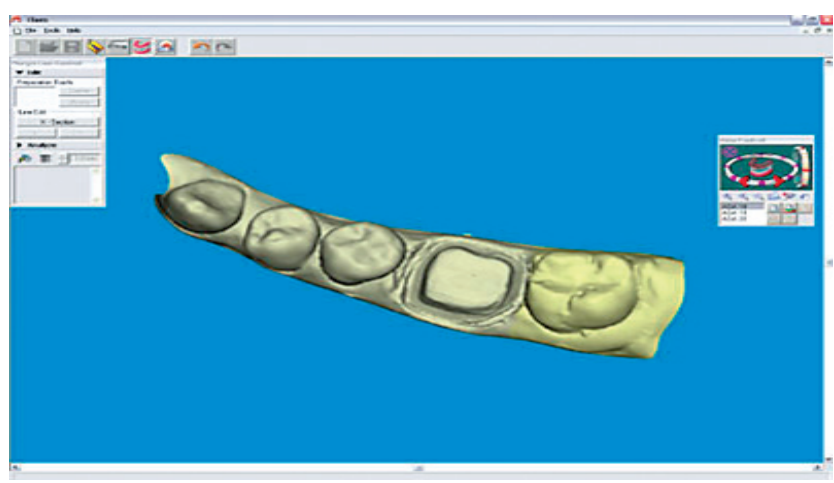

Figure 5: Scanned Abutments (Sample image) as it appears on computer software: Courtesy: www.wikipedia.com and image search. ${ }^{9}$ 
Table 1: Comparing the 3 scanner systems. ${ }^{4}$

\begin{tabular}{|c|c|c|c|}
\hline Features & Cadent iTero & 3 MLava C.O.S. & Sirona Cerec AC \\
\hline Optical Technology & $\begin{array}{l}\text { Parallel Confocal/Tele } \\
\text { centric }\end{array}$ & $\begin{array}{l}\text { Wave front Sampling } \\
\text { Technology } \\
\text { (3D in Motion) }\end{array}$ & LED/Laser Sampling \\
\hline Powder Required & No & Yes & Yes/opti spray \\
\hline Focal Depth & $13.5 \mathrm{~mm} \mathrm{1:1} \mathrm{exact} \mathrm{focus}$ & Range from 5 to $15 \mathrm{~mm}$ & Range from 5 to $15 \mathrm{~mm}$ \\
\hline Indications & All & Up to $4 U B$, and singles & All \\
\hline Models & $\begin{array}{l}\text { Milled/Polyurethane. } \\
\text { Removable dies, soft } \\
\text { tissue profile }\end{array}$ & $\begin{array}{l}\text { Additive/SLA in blue } \\
\text { resin. One solid model } \\
\text { and one working model. }\end{array}$ & $\begin{array}{l}\text { Additive/SLA; } \\
\text { no tissue }\end{array}$ \\
\hline $\begin{array}{l}\text { Data Import/Export } \\
\text { for Digital Interface }\end{array}$ & $\begin{array}{l}\text { Major CAD front end } \\
\text { systems - Dental } \\
\text { Wings, } 3 \text { Shape, } \\
\text { CEREC In-Lab, } \\
\text { Standard STL Binary File. }\end{array}$ & LAVA & Cerec Connect \\
\hline Articulator & $\begin{array}{l}\text { All directions, attachment } \\
\text { system to Whip Mix full } \\
\text { articulator for } \\
\text { complex cases }\end{array}$ & $\begin{array}{l}\text { Articulated; centric } \\
\text { and lateral } \\
\text { excursions }\end{array}$ & Hinge-only \\
\hline
\end{tabular}

to scan the margins if not visible properly. The tooth dried is then coated lightly with titanium dioxide to provide contrast points for scanning, improve speed of recording and enhance the recording of 3D image.

3. Third, scanner, which is same as intraoral camera is ready to scan the images. I mages are taken from all angles and a 3D image is produced in the software of the prepared tooth and the adjoining teeth. Then an image is taken for the occlusion for which the patient is told close mouth in maximum intercuspation.

4. Fourth, the scanned image is then sent to the concerned laboratory or an in office milling machine with patient details for its prosthesis.

In newer scanner systems, the only difference in above technique is that there is no need to apply powder coating on the tooth surface as good results are achieved in the improved systems without it (Figure 5).

\section{CONS OF DIGITAL IMPRESSIONS}

We al ready know about how the digital impression can be useful and helpful not only to us, but also for some patients who have gagging problem. So now we also take a look at the cons or rather shortcomings of these digital impressions

First, the machines available right now are pretty bulky and heavy and tend to occupy considerableamount of space especially wherespace is a constraint.

Second, If not scanned properly or not according to above said procedure the images won't be proper and that would affect the making of the restoration.

Third, as of now the entire system is costly, even costly than an OPG machine. So not easily affordable for everyone, plus the milling systems are also costly and not every laboratory would have the required milling machine. 
Fourth, Laboratory should have the required computer software to accept digital impression and milling machine to make a crown from it or one should have in-office milling machines which are in turn very costly.

Fifth, it is essential to follow basic prosthodontic principles and proper tissue management protocols in order to capture a highquality digital impression.7

Sixth, the clinician and the technologist should have sufficient knowledge and should be trained to operate and calibrate the system. ${ }^{8}$

\section{CONCLUSION}

Dentistry today has advanced to a great extent and with incorporation of technology, it has reached new heights. These digital impressions had been introduced long back but are gaining popularity now. They are widely used in developed countries like the US and UK, but in other countries Like India they are not in much use. With the improvements in hardware, software and decrease in cost and ease of use, many dentists are willing to integrate this technology. Though they are costly but are very cost effective in the long run. Use of a digital scanner can help dentists quickly identify and correct hard and soft tissue management issues before they become a problem in the model or final restoration.
Once the above shortcomings are overcome, technology use can be maximized, both for restorations and for educational purposes. ${ }^{7}$

\section{References}

1. Soll J ordan, Digital Impression Taking: A New Paradigm. Oral Health J Canada 2012.

2. Zweig Allan, I mproving impressions: Go Digital! Dentistry Today Nov 2009 edition.

3. Erickson Donald, Reduce seating times with digital technology: A Case Report Dentistry Today Sept 2010 edition.

4. Lowe Robert, CAD/CAM Dentistry and Chairside Digital I mpression Making, www.indeedce.com/Courses/2045/PDF .

5. Bonek S, Yakas M, Brown L, Digitalizing Dental Impressions. The Dental Advisor 2014.

6. Weston J, Roberts M. Digital Impressions: A Dentist's and a Laboratory Technician's Perspectives. J Cos Dent 2013; 29(2):52-62.

7. Ramsey CD. 15 Tips for Making a Great ImpressionDigitally. J Cos Dent 2013; 29(2).

8. Begum A, Ahmed R, Islam M. Digital impression. City Dent Col J 2012; 9(2):31-34.

9. Images From internet websites: www.wikipedia.com and image search.

\section{Gain quick access to our journal online View our journal at www.nacd.in}

